\title{
Integrated exposure-response analysis of efficacy and safety of lurbinectedin to support the dose regimen in small-cell lung cancer
}

\author{
Carlos Fernández-Teruel $^{1}$ (D) $\cdot$ Salvador Fudio $^{1}$ (D) $\cdot$ Rubin Lubomirov $^{1}$ (D)
}

Received: 6 August 2021 / Accepted: 10 October 2021 / Published online: 5 November 2021

(c) The Author(s) 2021

\begin{abstract}
Purpose These exposure-response (E-R) analyses integrated lurbinectedin effects on key efficacy and safety variables in relapsed SCLC to determine the adequacy of the dose regimen of $3.2 \mathrm{mg} / \mathrm{m}^{2} 1-\mathrm{h}$ intravenous infusion every 3 weeks (q3wk). Methods Logistic models and Cox regression analyses were applied to correlate lurbinectedin exposure metrics $\left(\mathrm{AUC}_{t o t}\right.$ and $\mathrm{AUC}_{u}$ ) with efficacy and safety endpoints: objective response rate (ORR) and overall survival (OS) in SCLC patients $(n=99)$ treated in study B-005 with $3.2 \mathrm{mg} / \mathrm{m}^{2} \mathrm{q} 3 \mathrm{wk}$, and incidence of grade 4 (G4) neutropenia and grade 3-4 (G $\left.\geq 3\right)$ thrombocytopenia in a pool of cancer patients from single-agent phase I to III studies $(n=692)$ treated at a wide range of doses. A clinical utility index was used to assess the appropriateness of the selected dose.

Results Effect of lurbinectedin $\mathrm{AUC}_{u}$ on ORR best fitted to a sigmoid-maximal response $\left(E_{\max }\right)$ logistic model, where $E_{\max }$ was dependent on chemotherapy-free interval (CTFI). Cox regression analysis with OS found relationships with both CTFI and $\mathrm{AUC}_{u}$. An $E_{\max }$ logistic model for $\mathrm{G} 4$ neutropenia and a linear logistic model for $\mathrm{G} \geq 3$ thrombocytopenia, which retained platelets and albumin at baseline and body surface area, best fitted to $\mathrm{AUC}_{t o t}$ and $\mathrm{AUC}_{u}$. $\mathrm{AUC}_{u}$ between approximately 1000 and $1700 \mathrm{ng} \cdot \mathrm{h} / \mathrm{L}$ provided the best benefit/risk ratio, and the dose of $3.2 \mathrm{mg} / \mathrm{m}^{2}$ provided median $\mathrm{AUC}_{u}$ of $1400 \mathrm{ng} \cdot \mathrm{h} / \mathrm{L}$, thus maximizing the proportion of patients within that lurbinectedin target exposure range.

Conclusions The relationships evidenced in this integrated E-R analysis support a favorable benefit-risk profile for lurbinectedin $3.2 \mathrm{mg} / \mathrm{m}^{2} \mathrm{q} 3 \mathrm{wk}$.

Trial registration Clinicaltrials.gov: NCT02454972; registered May 27, 2015.
\end{abstract}

Keywords Lurbinectedin $\cdot$ Exposure-response $\cdot$ Pharmacokinetics $\cdot$ Small-cell lung cancer $\cdot$ Clinical utility index

\section{Introduction}

Lung cancer is the leading cause of cancer deaths worldwide. Small-cell lung cancer (SCLC) accounts for about $15 \%$ of lung cancers overall and is a particularly aggressive neoplasm with a 5 -year survival rate of $<5 \%$. Little progress has been made in improving the outcome for patients with this malignancy over the past 30 years. When patients with SCLC relapse, few therapeutic options are available. Until recently, topotecan was the only approved drug for secondline treatment of patients with a chemotherapy-free interval (CTFI) longer than 60 days. However, topotecan use is challenging because of its associated hematological toxicities

Rubin Lubomirov

rlubomirov@pharmamar.com

1 Pharma Mar, S.A., Avda. De los Reyes, 1, Pol. Ind. La Mina-Norte, 28770 Colmenar Viejo, Madrid, Spain and relatively modest clinical benefit (response in around $16 \%$ of patients and median overall survival of $6-8$ months) [1-6].

Lurbinectedin is a selective inhibitor of oncogenic transcription that binds preferentially to guanines located in the GC-rich regulatory areas of DNA gene promoters [7, 8]. The drug, thus, prevents binding of transcription factors to their recognition sequences, thereby inhibiting oncogenic transcription and leading to cell cycle arrest and tumor cell apoptosis [9]. Lurbinectedin has a direct effect on the tumor microenvironment by modifying the immune-regulatory properties of tumor associated macrophages, where it significantly inhibits the transcription of CCL2, CXCL8, and VEGF [10].

Lurbinectedin is highly protein-bound, and metabolism by cytochrome P450 (CYP) 3A is the major clearance mechanism [11]. Main metabolites of lurbinectedin did not show a significant contribution to the overall active moiety [12]. A 
population pharmacokinetic (PopPK) analysis [13] with data from 443 cancer patients suggested that an open three-compartment model with linear disposition described the time course of total plasma lurbinectedin concentrations. The estimate for the total body clearance of drug from plasma $\left(\mathrm{CL}_{\text {tot }}\right)$ was $11.2 \mathrm{~L} / \mathrm{h}$, corresponding to a blood $\mathrm{CL}$ of $\sim 17$ $\mathrm{L} / \mathrm{h}$, thus reflecting a low extraction ratio of 0.19 . Apparent volume at steady state was $438 \mathrm{~L}$. High $\alpha$-1-acid glycoprotein (AAG), C-reactive protein (CRP), and low albumin reduced clearance by $28 \%, 20 \%$, and $20 \%$, respectively. Coadministration of CYP3A inhibitors reduced clearance by $30 \%$.

The first-in-human dose-finding study of lurbinectedin in patients with advanced solid tumors (A-001) [14] defined the recommended dose (RD) at $7.0 \mathrm{mg}$ flat dose (FD) (equivalent to $4.0 \mathrm{mg} / \mathrm{m}^{2}$ ) as a 1 -h infusion every 3 weeks (q3wk), since pharmacokinetic analyses showed no relationship between CL and body surface area (BSA). Mild and moderate reversible myelosuppression was the most relevant toxicity. A second dose-finding study (A-005) [15] exploring an alternative regimen (days 1 and $8 \mathrm{q} 3 \mathrm{wk}$ ) found a higher incidence of dose-limiting toxicities (21\% vs. $7 \%$ ) at the RD (5 mg FD), more cycle delays, and poorer treatment compliance than the A-001 study. After using the $7.0 \mathrm{mg}$ FD q3wk regimen in early phase II studies, semi-mechanistic pharmacokinetic-pharmacodynamic analyses were developed to model the time course of neutrophils and platelets and to explore alternative dose regimes [16]. Simulations showed that BSA-based dosed $3.2 \mathrm{mg} / \mathrm{m}^{2} \mathrm{q} 3 \mathrm{wk}$ reduced the incidence of G4 neutropenia and thrombocytopenia by $20 \%$ and $80 \%$, respectively, compared to $7.0 \mathrm{mg}$ FD q3wk. Therefore, $3.2 \mathrm{mg} / \mathrm{m}^{2} \mathrm{q} 3 \mathrm{wk}$ was selected as the starting dose for further studies.

Clinical efficacy and safety of lurbinectedin in patients with relapsed SCLC $(n=105)$ as well as other aggressive malignancies $(n=230)$ were evaluated in phase II, singlearm basket study B-005 [17]. Patients received lurbinectedin $3.2 \mathrm{mg} / \mathrm{m}^{2} \mathrm{q} 3 \mathrm{wk}$, with support of secondary prophylaxis with granulocyte colony-stimulating factor (G-CSF) when needed. In the overall population $(n=335)$, the incidences of G4 neutropenia $\left(<0.5 \times 10^{9} / \mathrm{L}\right)$ and $\mathrm{G} \geq 3$ thrombocytopenia $\left(<50 \times 10^{9} / \mathrm{L}\right)$ in cycle 1 were $16.2 \%$ and $6.0 \%$, respectively. In the SCLC cohort, lurbinectedin was efficacious in increasing the median objective response rate (ORR) in patients with resistant (22\% [95\% CI 11.2-37.1] and sensitive disease 45.0\% [95\% CI 32.1-58.4], by Independent Review Committee [IRC] $(n=96)$, and in extending the overall survival (OS) in patients with resistant (5.0 months [95\% CI 4.1-6.3]) and sensitive disease (11.9 months [95\% CI 9.7-16.2]). In the responders, median duration of response was 5.1 months (95\% CI 4.9-6.4 months). Based on these results, on June 15, 2020, the US Food and Drug Administration (FDA) granted accelerated approval to lurbinectedin monotherapy in SCLC that has relapsed from platinum compound-based first-line chemotherapy [11].

For the new drug application, the FDA requested justification of the $3.2 \mathrm{mg} / \mathrm{m}^{2} \mathrm{q} 3 \mathrm{wk}$ dose regimen with integrated exposure-response (E-R) analysis for efficacy and safety, which is presented herein.

Therefore, the purpose of this study was to characterize the relationships between lurbinectedin plasma exposure and both efficacy and safety endpoints, and to evaluate the potential influences of risk factors associated with these outcomes. A clinical utility index (CUI) was developed to manage safety and efficacy as a single measure, with the aim of determining the adequacy of the selected dose regimen.

\section{Methods}

\section{Patients}

The database from a previous PopPK analysis [13] was updated with late phase II and III studies and restricted to patients given lurbinectedin as a single agent $(n=755)$, as summarized in Online Resource Supplementary Table S1. Exposure-efficacy analyses were based on available exposure and efficacy data from SCLC patients treated with single-agent lurbinectedin from study B-005 $(n=99)$, and exposure-safety analyses were based on all single-agent lurbinectedin studies in non-hematological malignancies when the agent was given q3wk $(n=644)$ (see Online Resource Supplementary Table S1). All studies were carried out in accordance with principles for human experimentation as defined in the Declaration of Helsinki and were approved by the human investigational review board/ethics committee of each trial center, as required by International Council for Harmonisation of Technical Requirements for Pharmaceuticals for Human Use Guidelines for Good Clinical Practice. Informed consent was obtained from each patient after each was informed of the potential risks and benefits, as well as the investigational nature of each trial.

\section{Lurbinectedin plasma concentration measurement, ORR and OS definition, and neutrophil and platelet count determination}

Total plasma concentrations of lurbinectedin were measured using a high-performance liquid chromatography tandem mass spectroscopy assay (in preparation). The lower limit of quantitation for the assay was set to $0.1 \mathrm{ng} / \mathrm{mL}$. The withinand between-day precision ranged from 2.7 to $12.9 \%$ and from 5.1 to $10.7 \%$, respectively. The within- and betweenday accuracy (bias) ranged from -10 to $12 \%$ and from -5 to $6 \%$, respectively. Additional details are provided in Supplementary Methods. 
ORR was defined as the percentage of patients with complete or partial response defined per Investigator's Assessment and confirmed by Independent Radiology review Committee, using RECIST v.1.1 [18]. Radiological tumor assessments were done at baseline, and every two cycles from the onset of the study treatment until cycle 6 or evidence of disease progression. After cycle 6, tumor assessment was performed every three cycles until evidence of disease progression. If an objective response was observed, according to the RECIST v.1.1, it had to be confirmed by the same method at least 4 weeks after the date of the first documentation of response. OS was defined as the time from the date of treatment to the date of death or last contact.

Total neutrophil and platelet counts were assessed using routine complete blood counts according to local site laboratories. NCI-CTCAE v.4. was used for the definition of G4 neutropenia and $\mathrm{G} \geq 3$ thrombocytopenia.

\section{Computer software}

Datasets were prepared using SAS Enterprise Guide v.7.11 HF3 (SAS Institute Inc., Cary, NC, USA). Population PK assessment and exposure-response (ORR and myelosuppression) modeling were conducted using NONMEM v.7.3.0, SAEM with interaction, and IMP estimation methods (GloboMax LLC, Hanover, MD, USA). Compilations were achieved using gfortran v.4.8.5 (Free Software Foundation, Inc., Boston, MA, USA). Graphical and all other statistical analyses, including evaluation of NONMEM outputs, were performed with Perl speaks NONMEM v.4.6.0 [19], R v.3.2.5 (R Foundation for Statistical Computing, Vienna, Austria), and packages Xpose v.4.5.3 [20] and ggplot2 v.2.2.0 [21]. For OS, Cox proportional-hazards models and Kaplan-Meier plots were performed with SAS Enterprise Guide v.7.11 HF3.

\section{Pharmacokinetic analysis and exposure metrics}

Lurbinectedin exposure during cycle 1 was selected for these exposure-response analyses because hematological toxicities were mostly observed in cycle 1 [16], and pharmacokinetics of lurbinectedin is not time-dependent [13]. Due to the low hepatic extraction ratio and high plasma protein binding of lurbinectedin, it was anticipated that unbound fraction of lurbinectedin was dependent on AAG and albumin levels and the $\left.\mathrm{AUC}_{t o t}\right)$. Consequently, $\mathrm{AUC}_{\text {tot }}$ and $\mathrm{AUC}_{u}$ during cycle 1 were selected as exposure metrics.

$\mathrm{AUC}_{t o t}$ was computed as dose/total clearance $\left(\mathrm{CL}_{t o t}\right)$, where empirical Bayesian estimates of individual $\mathrm{CL}_{\text {tot }}$ were obtained from the updated PopPK model. $\mathrm{AUC}_{u}$ was derived for individual patients from $\mathrm{AUC}_{t o t}, \mathrm{AAG}$ and albumin concentrations, and respective dissociation rate constants (Eq. 1, [22]); where the dissociation constants for
AAG $\left(K_{\mathrm{d} 1}=83.0 \mathrm{nM}\right)$ and albumin $\left(K_{\mathrm{d} 2}=45,650 \mathrm{nM}\right)$ were estimated in vitro by equilibrium dialysis,

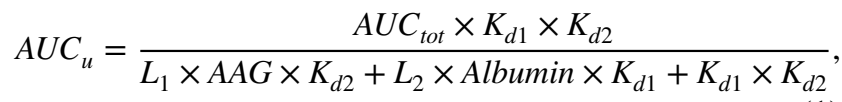

where $L_{1}$ and $L_{2}$ are the scaling factors between lurbinectedin (MW 784.881) and both AAG (MW 68,000) and albumin (MW 42,000). $L_{1}$ and $L_{2}$ were fixed to 0.01869 $\left(\mathrm{MW}_{\text {lurbinectedin }} / \mathrm{MW}_{\mathrm{AAG}}\right)$ and $0.01154\left(\mathrm{MW}_{\text {lurbinectedin }} /\right.$ $\left.\mathrm{MW}_{\text {Albumin }}\right)$, respectively, assuming a 1:1 molar binding ratio for both proteins. Finally, $\mathrm{AUC}_{u}$ values were transformed from $\mu \mathrm{g} \cdot \mathrm{h} / \mathrm{L}$ to $\mathrm{ng} \cdot \mathrm{h} / \mathrm{L}$ to increase the magnitude of the odds ratio estimates.

\section{Exposure-response analyses}

The primary efficacy endpoint of study B-005 was ORR by IRC. Radiological tumor assessments were done at baseline and every two cycles. CTFI (resistant disease [ $<90$ days] vs. sensitive disease [ $\geq 90$ days]) was included as a prognostic factor, and OS was a secondary endpoint.

The E-R analysis of safety included G4 neutropenia as a primary endpoint since it is the main dose-limiting toxicity associated with lurbinectedin. G4 neutropenia events generally involve the administration of G-CSF and eventually evolve to febrile neutropenia, a life-threatening adverse event. $\mathrm{G} \geq 3$ thrombocytopenia was included as a secondary endpoint; although occurrences are less frequent than G4 neutropenia, thrombocytopenia may lead to bleeding events and involve the administration of platelet transfusions.

Multivariate analyses were performed to simultaneously incorporate into the models the relationship between AUC and the significant prognostic factor (i.e., CTFI), as well as describe the predictive factors (i.e., AAG, albumin and BSA) identified in previous exploratory and univariate analyses, which showed a better correlation of $\mathrm{AUC}_{u}$ than $\mathrm{AUC}_{t o t}$. For E-R analysis of efficacy (ORR and OS), patients initially were classified into four equal-size groups based on the quartiles of $\mathrm{AUC}_{u}$. For ORR and safety outcomes, several mathematical models relating lurbinectedin $\mathrm{AUC}_{u}$ to the probability of response, $\mathrm{G} 4$ neutropenia and $\mathrm{G} \geq 3$ thrombocytopenia, were fitted in NONMEM. Initially, continuous $\mathrm{AUC}_{u}$ was assumed to be linearly related to the ORR logit and, if deemed appropriate, additional non-linear functions were used, including maximum lurbinectedin effect $\left(E_{\max }\right)$ and sigmoid- $E_{\max }$ logistic regression models. Odds ratios for either event were calculated. The final E-R models of safety (G4 neutropenia and $\mathrm{G} \geq 3$ thrombocytopenia) were used to run simulations ( $N=100$ replicates) to predict the effect of dose regimen modifications. For OS, Cox proportionalhazards models relating $\mathrm{AUC}_{u}$ to the hazard of death were developed. 


\section{Clinical utility index}

The relationship between the probability of ORR and the probability of G4 neutropenia was estimated by means of a CUI [23], a quantitative method to determine the optimal trade-offs between key drug efficacy and safety profile, by bringing them into the same scale. Considering that therapeutic options are scarce for second-line SCLC with low probability of response and that G4 neutropenia is clinically manageable with secondary prophylaxis of G-CSF and dose reductions as needed, a 2:1 weighting scheme was used for ORR and incidence of G4 neutropenia, for a more realistic clinical benefit assessment.

\section{Results}

\section{Pharmacokinetic analysis}

The final model, using 9176 total plasma concentrations from 755 patients treated at a wide range of lurbinectedin doses $\left(0.02-6.9 \mathrm{mg} / \mathrm{m}^{2}\right)$ with two dose regimens (day 1 $\mathrm{q} 3 \mathrm{wk}$ and days 1 and $8 \mathrm{q} 3 \mathrm{wk}$ ), is described in Eqs. 2-6. The parameter estimates and bootstrap of the PopPK model, including the statistically significant covariate effects on model parameters, are presented in Online Resource Supplementary Table S2.

$\boldsymbol{V}_{1, i}=\boldsymbol{V}_{1}\left(\frac{A A G_{i}}{121}\right)^{V_{1, A A G}}\left(1+\boldsymbol{V}_{1, A A G} \times\left(B S A_{i}-1.76\right)\right) e^{\eta V_{1}}$

$C L_{i}=C L\left(\frac{A A G_{i}}{121}\right)^{C L_{A A G}}\left(\frac{A L B_{i}}{4}\right)^{C L_{A L B}}\left(1+C L_{I N H} \times I N H\right) e^{\eta C L}$,

$V_{3, i}=V_{3}\left(\frac{A A G_{i}}{121}\right)^{V_{3, A A G}}\left(\frac{B S A_{i}}{1.76}\right)^{V_{3, A A G}}\left(1+V_{3, S E X F} \times S E X F\right) e^{\eta V_{3}}$,

$Q_{3, i}=Q_{3}\left(\frac{A A G_{i}}{121}\right)^{Q_{3, A A G}}\left(\frac{B S A_{i}}{1.76}\right)^{Q_{3, B S A}}\left(1+Q_{3, S E X F} \times S E X F\right) e^{\eta Q_{3}}$,

$V_{2, i}=\boldsymbol{V}_{2}\left(\frac{\boldsymbol{A} \boldsymbol{A} \boldsymbol{G}_{i}}{121}\right)^{\boldsymbol{V}_{2, \boldsymbol{A A G}}}\left(1+\boldsymbol{V}_{2, \boldsymbol{B S A}} \times\left(\boldsymbol{B S} \boldsymbol{A}_{i}-1.76\right)\right) e^{\eta \boldsymbol{V}_{2}}$

An open three-compartment model with linear elimination was able to describe the time course of total plasma concentration and its variability. An initial rapid distribution half-life $\left(t_{1 / 2}\right)$ of about $8-9$ min is followed by a slower $t_{1 / 2}$ of about $1.9 \mathrm{~h}$ and a terminal $t_{1 / 2}$ of about $51 \mathrm{~h}$, with the latter phase constituting a substantial portion of the overall
AUC. In study B-005, the median (range) of estimated lurbinectedin $\mathrm{AUC}_{\text {tot }}$ and $\mathrm{AUC}_{u}$ at $3.2 \mathrm{mg} / \mathrm{m}^{2}$ in study B-005 were 493 (176-1083) $\mu \mathrm{g} \cdot \mathrm{h} / \mathrm{L}$ and 1400 (433-3136) $\mathrm{ng} \cdot \mathrm{h} / \mathrm{L}$, respectively.

\section{Exposure-response analysis}

\section{Objective response rate}

Among several linear and non-linear models examined, a sigmoid- $E_{\max }$ model for $\mathrm{AUC}_{u}$, where CTFI modified the $E_{\max }$ parameter (Eq. 7), was found to best describe ORR data.

$\operatorname{logit}(\boldsymbol{O R R})=-10+\frac{\boldsymbol{E}_{\text {max }} \times \boldsymbol{A U} \boldsymbol{C}_{u}^{10}}{\boldsymbol{E C}_{50}^{10}+\boldsymbol{A U} \boldsymbol{C}_{u}^{10}}$,

where $\mathrm{EC}_{50}$ was the $\mathrm{AUC}_{u}$ that provided half $E_{\max }$ on ORR. Parameter estimates with relative standard errors (RSEs) in the final model are shown in Table 1. Observed and modelpredicted ORRs by IRC, stratified by CTFI, are depicted in Fig. 1. Figure 1 Relationship between ORR by IRC and $\mathrm{AUCu}$ stratified by CTFI; the maximum ORRs for patients with sensitive and resistant SCLC were $69.1 \%$ (95\% CI 49.3-83.8) and $18.1 \%$ (95\% CI 7.7-37.1), respectively, reaching its 95\% CI with $\mathrm{AUC}_{u}$ above 1337 and $1433 \mathrm{ng} \cdot \mathrm{h} / \mathrm{L}$.

\section{Overall survival}

Based on the differences between first quartile and upper quartiles of $\mathrm{AUC}_{u}$ and differences in OS between sensitive and resistant disease, upper quartiles (second to fourth) were pooled and compared against the lowest quartile and stratified by CTFI (Fig. 2). In patients with resistant and sensitive disease, pooled $\mathrm{AUC}_{u}$ (first vs. second to fourth quartiles) showed statistically significant differences. Median overall survival in patients with resistant disease were 3.81 months (95\% CI 0.92-4.37) and 6.24 months (95\% CI 4.27-8.08) for first and upper quartiles, respectively, after the start of lurbinectedin treatment, while in patients with sensitive disease were 7.26 months (95\% CI 3.22-7.79) and 15.90 months (95\% CI 10.87-19.29), respectively (Fig. 2). Additionally, in a multivariate Cox regression analysis including CTFI and $\mathrm{AUC}_{u}$ as a continuous variable, relationships were found for both CTFI and $\mathrm{AUC}_{u}$, with hazard ratios of 0.22 (95\% CI 0.12-0.39) and 0.41 (95\% CI 0.23-0.72), respectively (Table 2). This translates to a 4.6-fold higher risk of death, and a 2.5-fold lower risk of death per unit increase in $\mathrm{AUC}_{u}(\mu \mathrm{g} \cdot \mathrm{h} / \mathrm{L})$, in patients with resistant disease than in patients with sensitive disease. 
Table 1 Parameter estimates and their uncertainty for the final ORR, G4 neutropenia and $\mathrm{G} \geq 3$ thrombocytopenia logistic regression models

\begin{tabular}{|c|c|}
\hline Parameter & Estimate (RSE\%) \\
\hline \multicolumn{2}{|l|}{ ORR model } \\
\hline$E_{\max }$ resistant & $8.49(5.88)$ \\
\hline$E_{\max }$ sensitive & $10.81(3.94)$ \\
\hline $\mathrm{EC}_{50}(\mathrm{ng} \cdot \mathrm{h} / \mathrm{L})$ & $877(7.73)$ \\
\hline \multicolumn{2}{|c|}{ G4 neutropenia model based on $\mathrm{AUC}_{u}$} \\
\hline$E_{\max }$ & $9.28(3.23)$ \\
\hline $\mathrm{EC}_{50}(\mathrm{ng} \cdot \mathrm{h} / \mathrm{L})$ & $65.4(35.0)$ \\
\hline \multicolumn{2}{|c|}{$\mathrm{G} 4$ neutropenia model based on $\mathrm{AUC}_{\text {tot }}$} \\
\hline$E_{\max }$ & $11.4(4.18)$ \\
\hline $\mathrm{EC}_{50}(\mu \mathrm{g} \cdot \mathrm{h} / \mathrm{L})$ & $561(17.6)$ \\
\hline \multicolumn{2}{|c|}{$\mathrm{G} \geq 3$ thrombocytopenia model based on $\mathrm{AUC}_{u}$} \\
\hline Baseline & $-4.61(8.32)$ \\
\hline Slope $_{\mathrm{AUCu}}(\mathrm{ng} \cdot \mathrm{h} / \mathrm{L})$ & $0.000873(19.9)$ \\
\hline Slope $_{\text {Platelets }}$ & $-0.01(41.9)$ \\
\hline Slope $_{\text {BSA }}$ & $-2.58(31.9)$ \\
\hline Slope $_{\text {Albumin }}$ & $-1.04(36.9)$ \\
\hline \multicolumn{2}{|c|}{$\mathrm{G} \geq 3$ thrombocytopenia model based on $\mathrm{AUC}_{t o t}$} \\
\hline Baseline & $-3.96(10.1)$ \\
\hline Slope $_{\mathrm{AUCu}}(\mu \mathrm{g} \cdot \mathrm{h} / \mathrm{L})$ & $0.00136(34.2)$ \\
\hline Slope $_{\text {Platelets }}$ & $-0.00635(45.5)$ \\
\hline Slope $_{\text {BSA }}$ & $-2.31(32.9)$ \\
\hline Slope $_{\text {Albumin }}$ & $-1.23(35.8)$ \\
\hline Slope $_{\mathrm{AAG}}$ & $-0.00911(45.5)$ \\
\hline
\end{tabular}

$A A G \alpha-1$-acid glycoprotein, $A U C_{\text {tot }}$ total plasma area under the concentration-time curve, $A U C_{u}$ unbound plasma area under the concentration-time curve, $B S A$ body surface area, $E_{\max }$ maximal response, $E C_{50}$ half maximal effective concentration, $G$ grade, ORR objective response rate, $S E$ relative standard error

\section{G4 neutropenia}

Several covariates were explored to assess their impact on G4 neutropenia: dose, neutrophils at baseline, albumin, AAG, and BSA. After a number of models were tested using continuous metrics for exposure, an $E_{\max }$ model based on changes of $\mathrm{AUC}_{u}$, where the base parameter was fixed to a low value $(-10)$, was finally selected. An equivalent model with $\mathrm{AUC}_{\text {tot }}$ presented higher objective function value (ofv), although this improved when AAG was included.

$\operatorname{logit}($ neutropeniagrade 4$)=$ Base $+\frac{E_{\text {max }} \times A U C}{E C_{50}+A U C}$

Figure 3 shows the probability of G4 neutropenia predicted by the model for $\mathrm{AUC}_{u}$. Parameter estimates with $\mathrm{RSE}$ in the final models based on $\mathrm{AUC}_{u}$ and $\mathrm{AUC}_{\text {tot }}$ are shown in Table 1.
$\mathrm{AUC}_{u}$ from study B-005 was bootstrapped to predict the incidence of G4 neutropenia at doses of 3.2, 2.6, and $2.0 \mathrm{mg} /$ $\mathrm{m}^{2}$, which correspond to the recommended dose, the first and second $20 \%$ dose reductions, as recommended in the label. The resulting decreases in lurbinectedin exposure following the first and second $20 \%$ dose reductions are expected to lower the incidence of G4 neutropenia from the $16.5 \%$ (95\% CI 16.4-16.6) incidence at $3.2 \mathrm{mg} / \mathrm{m}^{2}$ to $11.3 \%(95 \%$ CI 11.2-11.4), and 7.5\% (7.4-7.7), at 2.6, and $2.0 \mathrm{mg} / \mathrm{m}^{2}$.

\section{$\mathrm{G} \geq 3$ thrombocytopenia}

Several models for $\mathrm{G} \geq 3$ thrombocytopenia exploring a number of covariates (i.e., dose, platelets at baseline, albumin, AAG, BSA) were examined. A linear logistic model based on $\mathrm{AUC}_{u}$ showed the best fit, where higher values of retained covariates reduced the likelihood of $\mathrm{G} \geq 3$ thrombocytopenia.

\section{logit(thrombocytopeniagrade $\geq 3$ )}

$$
\begin{aligned}
= & \text { Baseline } \text { Slope }_{A U C_{u}} \\
& \times \text { AUC }_{u_{i}}+\text { Slope }_{\text {Platelets }} \\
& \times\left(\text { Platelets }_{i}-243\right)+\text { Slope }_{B S A} \\
& \times\left(\text { BSA }_{i}-1.75\right)+\text { Slope }_{\text {Albumin }} \\
& \times\left(\text { Albumin }_{i}-4.0\right)
\end{aligned}
$$

where $A U C_{u_{i}}$, Platelets $_{i}, B S A_{i}$, and Albumin $_{i}$ correspond to the individual values for $\mathrm{AUC}_{u}$, platelets, BSA, and albumin at baseline, respectively, for the $i$ th individual. An equivalent model based on $\mathrm{AUC}_{\text {tot }}$ showed a higher ofv, which improved when AAG was added (see Table 1).

Since BSA was not associated to $C L$ in the PopPK model, although it did to $V_{1}, V_{2}, V_{3}$, and $Q_{3}$, confounding factors causing the effect of BSA on thrombocytopenia were explored. In this sense, factors included in a previously developed semi-mechanistic PKPD model of lurbinectedin on platelets [16] were analyzed. Apart from BSA (affecting $\mathrm{EC}_{50}$ ), baseline platelets (as part of the structural model) and tumor type (affecting $\mathrm{EC}_{50}$ ), with pancreas and ovarian as more sensitive tumors, were the detected covariates. BSA was neither related with baseline platelets nor with tumor type, so confounders affecting the relationship between BSA and thrombocytopenia are unlikely.

As described above for neutropenia, $\mathrm{AUC}_{u}$ from study B-005 was bootstrapped to predict the incidence of $\mathrm{G} \geq 3$ thrombocytopenia at doses of $3.2,2.6$, and $2.0 \mathrm{mg} / \mathrm{m}^{2}$. The resulting decreases in lurbinectedin exposure following the first and second $20 \%$ dose reductions are expected to lower the incidence of G4 neutropenia from the $4.8 \%(95 \% \mathrm{CI}$ $4.7-4.9)$ incidence at $3.2 \mathrm{mg} / \mathrm{m}^{2}$ to $3.5 \%$ (95\% CI $\left.3.4-3.5\right)$, and $2.75 \%(2.6-2.7)$, at 2.6 , and $2.0 \mathrm{mg} / \mathrm{m}^{2}$. 
a

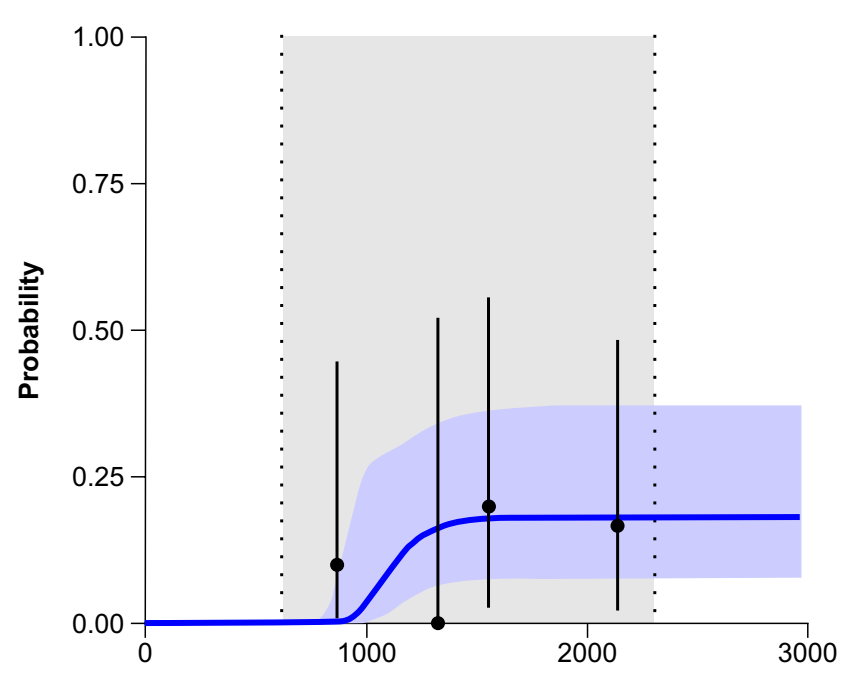

b

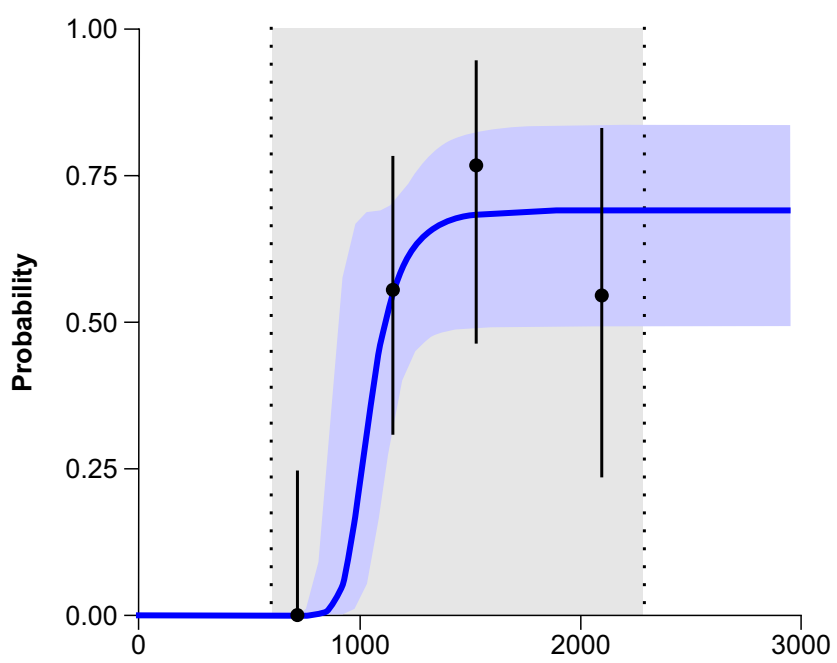

\section{$\mathrm{AUC}_{\mathrm{u}}[\mathrm{ng} \cdot \mathrm{h} / \mathrm{L}]$}

Fig. 1 Relationship between ORR by IRC and $\mathrm{AUCu}$ stratified by CTFI. Solid black dots represent the proportion of responders grouped by quartiles of $\mathrm{AUC}_{u}$ and plotted at the median $\mathrm{AUC}_{u}$ for each quartile in resistant (a) and sensitive (b) patients. Bars represent the $95 \%$ CI for the proportion of each quartile. Curve and blue shaded area represent predicted values and 95\% CI of model-predicted

a

I Censored

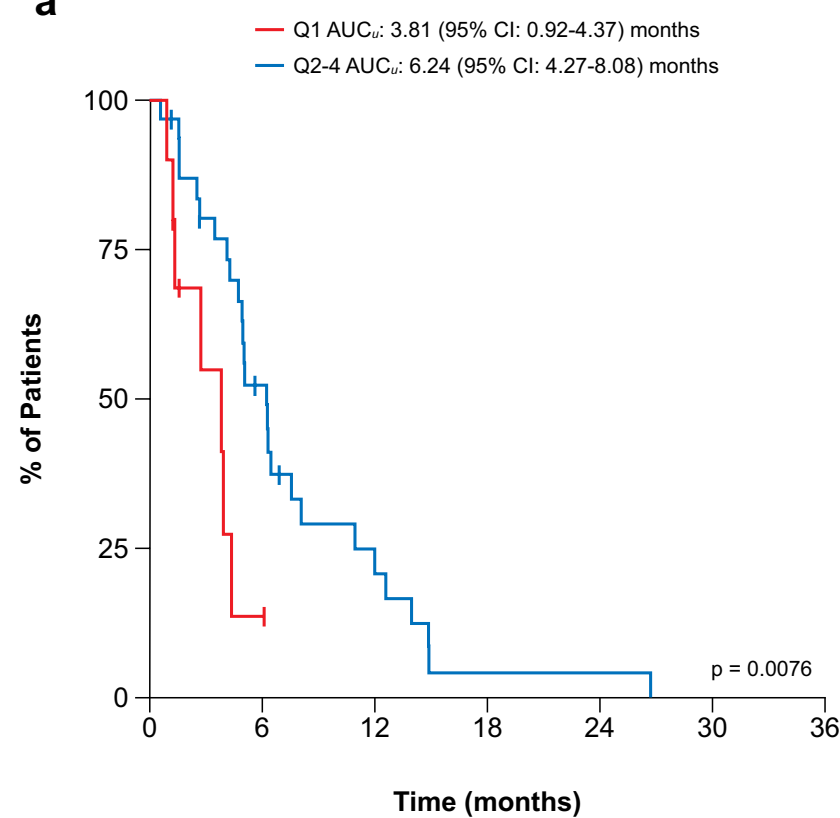

Fig. 2 Kaplan-Meier plots for OS versus pooled $\mathrm{AUC}_{u}$ (first vs. second to fourth quartiles), stratified by CTFI (a, resistant; $\mathbf{b}$, sensitive). Q1 $\mathrm{AUC}_{u}$ : first quartile of $\mathrm{AUC}_{u}$; $\mathrm{Q} 2-4 \mathrm{AUC}_{u}$ : second to fourth quar-
ORR, respectively. The vertical point lines and the gray shaded area represent the $95 \%$ prediction interval of the observed $\mathrm{AUC}_{u}$. $A U C$ ${ }_{u}$ unbound plasma area under the concentration-time curve, $C I$ confidence interval, $C T F I$ chemotherapy-free interval, $I R C$ independent review committee, $O R R$ objective response rate

\section{b}

I Censored

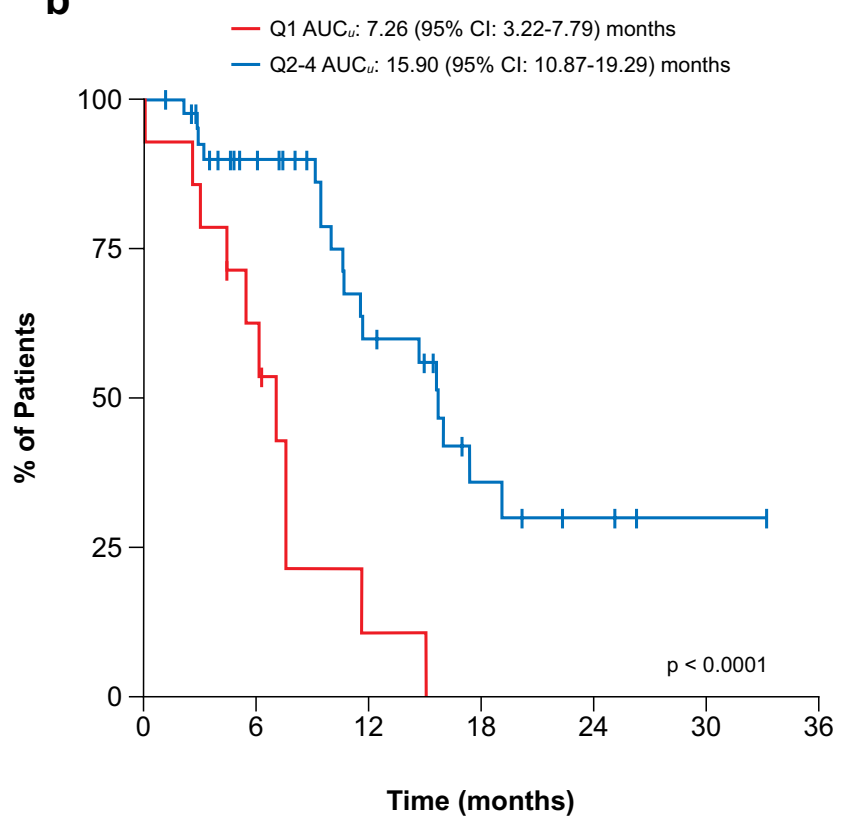

tiles of $\mathrm{AUC}_{u} . A U C_{u}$ unbound plasma area under the concentrationtime curve, $C T F I$ chemotherapy-free interval, $O S$ overall survival 
Table 2 Cox regression analysis with OS by CTFI and $\mathrm{AUC}_{u}$

\begin{tabular}{|c|c|c|c|c|c|c|c|c|}
\hline Parameter & & DF & $\begin{array}{l}\text { Parameter } \\
\text { estimate }\end{array}$ & Standard error & Chi-square & $\operatorname{Pr}>$ ChiSq & Hazard ratio & $95 \% \mathrm{CI}$ \\
\hline CTFI & 2 & 1 & -1.52 & 0.29 & 26.74 & $<0.0001$ & 0.22 & $(0.12-0.39)$ \\
\hline $\mathrm{AUC}_{u}$ & & 1 & -0.90 & 0.29 & 9.52 & 0.002 & 0.41 & $(0.23-0.72)$ \\
\hline
\end{tabular}

$A U C_{u}$, unbound plasma area under the concentration-time curve, ChiSq Chi-square, CTFI chemotherapyfree interval, $D F$ degrees of freedom, $O S$ overall survival, $P r>C h i S q$ associated $p$ value

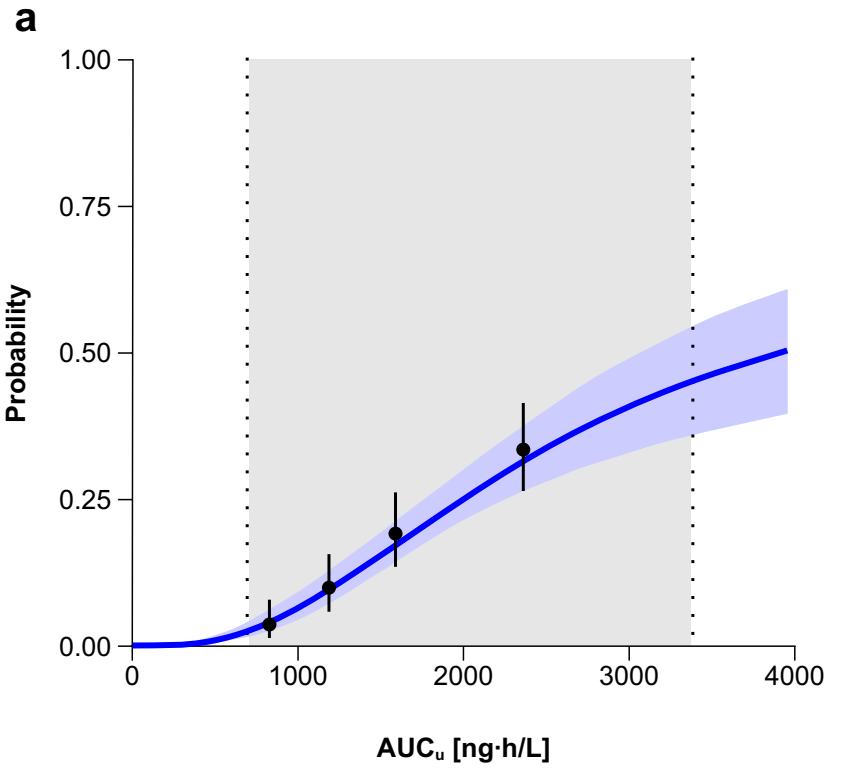

Fig. 3 Relationship between $\mathrm{AUC}_{u}$ and G4 neutropenia (a) and G $\geq 3$ thrombocytopenia (b). Solid black dots represent the G4 neutropenia or $\mathrm{G} \geq 3$ thrombocytopenia incidence grouped by quartiles of AUC ${ }_{u}$ and plotted at the median $\mathrm{AUC}_{u}$ for each quartile. The bars represent the $95 \%$ confidence interval for the proportion of each quartile. Curve and blue shaded area represent predicted values and $95 \%$ con-

As BSA was retained in the model, the incidence of $\mathrm{G} \geq 3$ thrombocytopenia at a fixed dose of $5.6 \mathrm{mg}$ (equivalent to $3.2 \mathrm{mg} / \mathrm{m}^{2}$ for a BSA of $1.75 \mathrm{~m}^{2}$ ) increased a $16 \%$ in patients lower BSA. Less variation in the incidence of $\mathrm{G} \geq 3$ thrombocytopenia was observed with BSA-based dosing: 6.4\% (95\% CI 5.3-8.1) in patients with lower BSA $\left(<1.64 \mathrm{~m}^{2}\right)$ and $3.1 \%$ (95\% CI 1.9-4.8) in patients with larger BSA; with FD, the incidences were $7.6 \%$ (95\% CI 6.2-9.5) and $2.5 \%$ (95\% CI $1.6-4.0)$, respectively.

\section{Clinical utility index}

To depict the adequacy of the dose regimen of $3.2 \mathrm{mg} / \mathrm{m}^{2}$ q3wk in terms of the relationship between the probability of ORR and the probability of G4 neutropenia, a CUI was estimated (Fig. 4). The best benefit/risk ratio appeared at lurbinectedin $\mathrm{AUC}_{u}$ between approximately 1000 and $1700 \mathrm{ng} \cdot \mathrm{h} / \mathrm{L}$. b

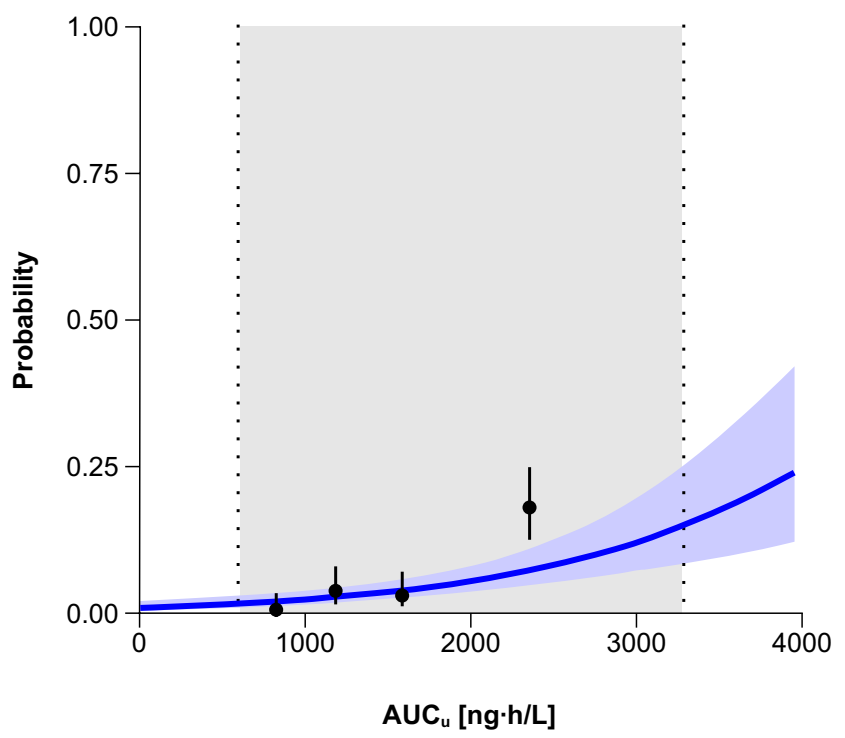

fidence intervals of model-predicted risk of $\mathrm{G} 4$ neutropenia or $\mathrm{G} \geq 3$ thrombocytopenia, respectively. The vertical point lines and the gray shaded area represent the $95 \%$ prediction interval of the observed $\mathrm{AUC}_{u}$ in patients treated at doses from 0.02 to $6.9 \mathrm{mg} / \mathrm{m}^{2} . A U C_{u}$ unbound plasma area under the concentration-time curve, $G$ grade

\section{Discussion}

This integrated E-R analysis indicates that lurbinectedin exposure was significantly associated with efficacy and safety outcomes. Maximal ORR and OS were found in patients with $\mathrm{AUC}_{u}$ from approximately $1400 \mathrm{ng} \cdot \mathrm{h} / \mathrm{L}$ and $1000 \mathrm{ng} \cdot \mathrm{h} / \mathrm{L}$, respectively, which may reveal that ORR is a more treatment directly linked outcome and, therefore, more $\mathrm{AUC}_{u}$ dependent, while OS may be more affected by other factors after treatment with lurbinectedin. The magnitude of lurbinectedin exposure effect on ORR (see Fig. 1) and OS see (Fig. 2) was dependent on CTFI. For patients with sensitive disease, the maximal ORR and the median survival were estimated to be $69.1 \%$ and 15.9 months for lurbinectedin $\mathrm{AUC}_{u}$ above $1337 \mathrm{ng} \cdot \mathrm{h} / \mathrm{L}$ and $1052 \mathrm{ng} \cdot \mathrm{h} / \mathrm{L}$, respectively. However, for patients with resistant disease, the ORR and 


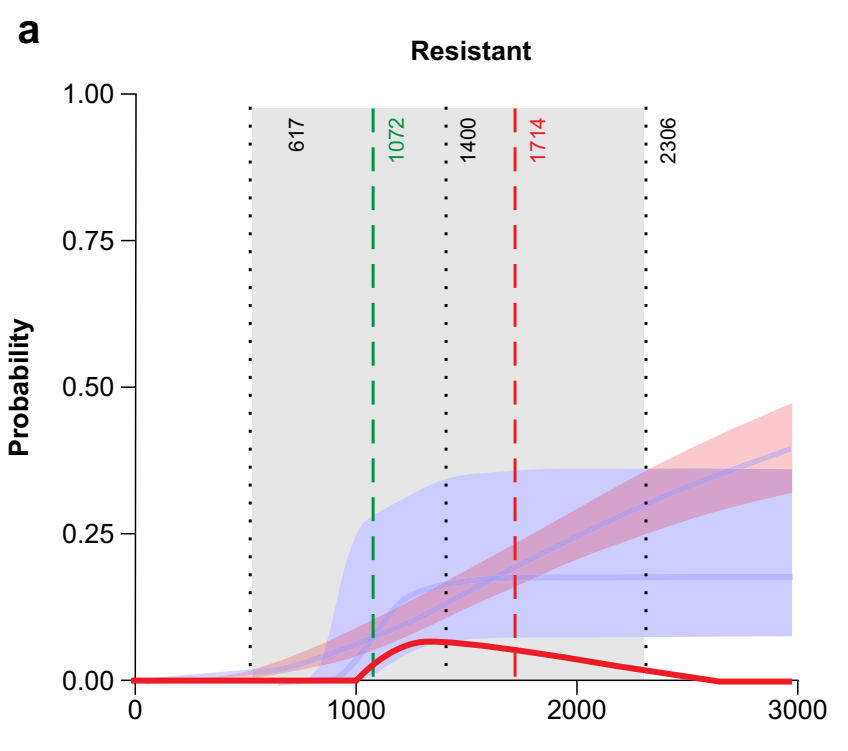

$\mathrm{AUC}_{\mathrm{u}}[\mathrm{ng} \cdot \mathrm{h} / \mathrm{L}]$ b

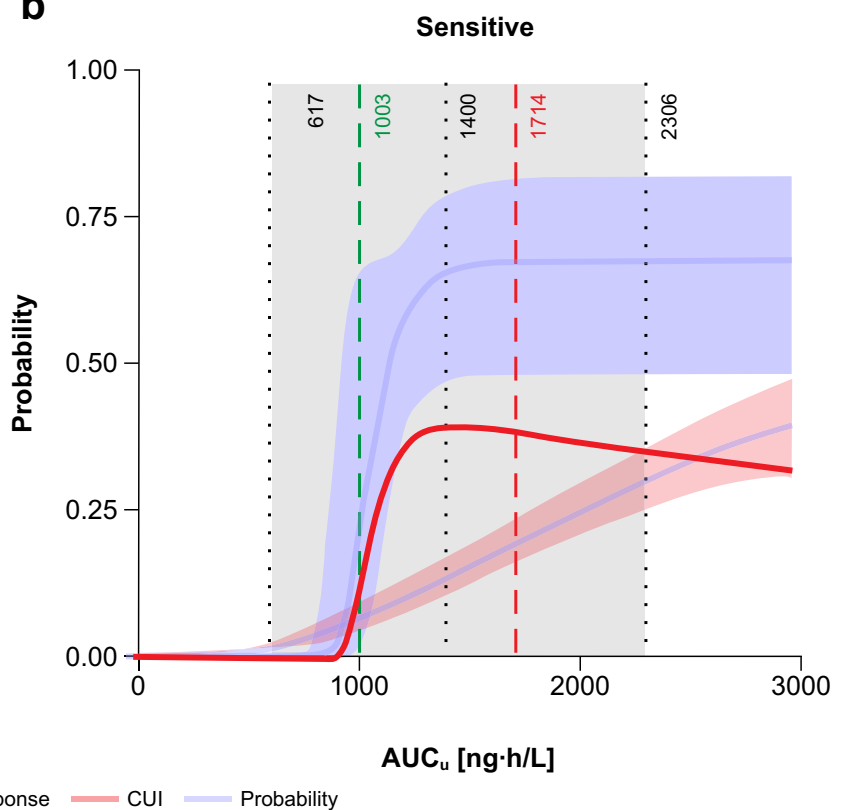

Fig. 4 Clinical utility index with $\mathrm{AUC}_{u}$ in resistant (a) and sensitive (b) SCLC patients. Dashed green vertical line is the lurbinectedin $\mathrm{AUC}_{u}$ providing an ORR of $7.5 \%$ (resistant) and 19.3\% (sensitive), which are the ORRs corresponding to topotecan. Dashed dark red vertical line is the $\mathrm{AUC}_{u}$ at which the probability of grade 4 neutro-

the median OS were estimated to be $18.1 \%$ and 6.2 months for $\mathrm{AUC}_{u}$ above $1433 \mathrm{ng} \cdot \mathrm{h} / \mathrm{L}$ and $1007 \mathrm{ng} \cdot \mathrm{h} / \mathrm{L}$, respectively.

Historical efficacy data from seven published clinical trials with topotecan in second-line SCLC (Online Resource Supplementary Table S3) suggest mean ORRs of 7.5\% (95\% CI 4.8-10.9, $n=322$ ) and 19.3\% (95\% CI 15.1-24.0, $n=327$ ) for resistant and sensitive SCLC patients, respectively. Therefore, based on these point estimates, lurbinectedin $\mathrm{AUC}_{u}$ above $1072 \mathrm{ng} \cdot \mathrm{h} / \mathrm{L}$ and $1003 \mathrm{ng} \cdot \mathrm{h} / \mathrm{L}$, which are similar to $\mathrm{EC}_{50}$ of ORR (Table 1), would improve the topotecan ORR, up to $18.1 \%$ and $69.1 \%$, for resistant and sensitive patients, respectively (see Fig. 4).

In terms of safety outcomes, the present analysis provides a robust relationship between lurbinectedin exposure and the probability of myelosuppression (see Fig. 3). Lurbinectedin $\mathrm{AUC}_{u}$ above $1714 \mathrm{ng} \cdot \mathrm{h} / \mathrm{L}$ increased the incidence of G4 neutropenia beyond 20\%. One or two sequential 20\% dose reductions during the course of treatment with lurbinectedin are recommended in the label to manage severe episodes of neutropenia or thrombocytopenia and improve lurbinectedin tolerability in patients who develop these toxicities after lurbinectedin treatment. The first dose reduction resulted in a G4 neutropenia and $\mathrm{G} \geq 3$ thrombocytopenia incidence relative decrease of $32 \%$ and $27 \%$, respectively. A second $20 \%$ dose reduction produced an additional decrease of $34 \%$ and $21 \%$. penia is $20 \%$. The gray shaded area represents the $95 \%$ prediction interval of the observed $\mathrm{AUC}_{u}$ in SCLC patients treated at $3.2 \mathrm{mg} /$ $\mathrm{m}^{2}$. Black dotted vertical lines are percentiles 5, 50, and 95 of $\mathrm{AUC}_{u}$. $A U C_{u}$ unbound plasma area under the concentration-time curve, $C U I$ clinical utility index, $G$ grade, $S C L C$ small-cell lung cancer

Moreover, the BSA-based dosing at $3.2 \mathrm{mg} / \mathrm{m}^{2}$ provides a $16 \%$ reduction in the incidence of severe thrombocytopenia in patients with $\mathrm{BSA}<1.65 \mathrm{~m}^{2}$, thus favoring the use of BSA-based dosing over flat dosing.

Consequently, $\mathrm{AUC}_{u}$ between approximately 1000 and $1700 \mathrm{ng} \cdot \mathrm{h} / \mathrm{L}$ provided the best benefit/risk ratio for lurbinectedin, and the recommended dosing regimen of $3.2 \mathrm{mg} / \mathrm{m}^{2}$ provided a median $\mathrm{AUC}_{u}$ of $1400 \mathrm{ng} \cdot \mathrm{h} / \mathrm{L}$, which maximizes the proportion of patients within this lurbinectedin target exposure range. Lowering the dose resulted in a dramatic drop in efficacy, whereas increasing the dose increased the incidence of severe hematological toxicity without apparent improvement in efficacy (see Fig. 4).

The main limitation of this study is that the exposure-efficacy analysis relies on a unique dose level. Nevertheless, a clear relationship between $\mathrm{AUC}_{u}$ and ORR was characterized, which was further endorsed by the relationship between the same exposure metric and OS. Another potential limitation is the lack of direct in vivo quantification of unbound lurbinectedin plasma concentrations, and, therefore, the estimation of individual $\mathrm{AUC}_{u}$ was based on the $\mathrm{AUC}_{t o t}, \mathrm{AAG}$, and albumin from each patient. In a published PopPK model, a reduction in total plasma CL associated with increased AAG and CRP and reduced albumin was detected [13]. Additional experiments were planned to elucidate the underlying reason of such an inflammatory pattern 
leading to a decreased CL. An in vitro plasma protein-binding study shed light in revealing the preferential affinity of lurbinectedin to $\mathrm{AAG}$, and dissociation constants for $\mathrm{AAG}$ and albumin could be calculated to allow $\mathrm{AUC}_{u}$ estimation. Unbound lurbinectedin plasma concentrations are being measured with a validated method in ongoing drug-drug interaction and organ impairment studies, so that a comparison between model-based estimated $\mathrm{AUC}_{u}$ and observed $\mathrm{AUC}_{u}$ can be made.

In this sense, the safety models presented herein established E-R relationships with both $\mathrm{AUC}_{u}$ and $\mathrm{AUC}_{t o t}$, by virtue of a large database of patients $(n=755)$ treated at a wide range of lurbinectedin doses, although model diagnostics showed a better fit of $\mathrm{AUC}_{u}$ over $\mathrm{AUC}_{\text {tot }}$. However, the efficacy model could not be fitted to $\mathrm{AUC}_{t o t}$, but only to $\mathrm{AUC}_{u}$. Given the low extraction ratio, lurbinectedin $\mathrm{AUC}_{\text {tot }}$ and unbound fraction were interfered by plasma protein levels, which vary substantially among cancer patients, while $\mathrm{AUC}_{u}$ remained unaffected [24]. $\mathrm{AUC}_{u}$ is more representative of active lurbinectedin AUC, thus exposing existing relationships with efficacy outcomes, regardless of the smaller efficacy database of patients $(n=99)$ treated at a single dose level.

\section{Conclusion}

The relationships evidenced in this integrated E-R analysis, with efficacy variables at a single dose level and safety variables at a wide range of doses, support a favorable benefit-risk profile for the approved lurbinectedin dose regimen of $3.2 \mathrm{mg} /$ $\mathrm{m}^{2} \mathrm{q} 3 \mathrm{wk}$. One or two sequential $20 \%$ dose reductions during the course of lurbinectedin treatment are adequate to manage patients who develop severe episodes of myelosuppression.

Supplementary Information The online version contains supplementary material available at https://doi.org/10.1007/s00280-021-04366-3.

Acknowledgements The study was sponsored by Pharma Mar. Pharma Mar contributed to the study design, research, and interpretation of the data, and the writing, review, and approval of the publication. We gratefully acknowledge the patients and their families; investigators and all the personnel who have participated in this trial, especially CM Fernández, V Alfaro, J Gómez, L Pérez-Ramos, E Asín, C Kahatt, A Zeaiter, and A Soto-Matos. Editorial assistance was provided by SciFluent Communications, Inc., and was financially supported by Jazz Pharmaceuticals.

Author contributions All authors contributed to the study conception and design as well as read and approved the final manuscript.

Funding The study was sponsored by Pharma Mar. Pharma Mar contributed to the study design, research, and interpretation of the data, and the writing, review, and approval of the publication.

Availability of data and material Qualified researchers may request access to data by contacting the corresponding author.
Code availability Qualified researchers may request access to model codes by contacting the corresponding author.

\section{Declarations}

Conflict of interest Salvador Fudio and Rubin Lubomirov are employees of Pharma Mar. Carlos Fernández-Teruel is a former employee of Pharma Mar. All authors may hold Pharma Mar stock or stock options.

Ethical approval All studies were carried out in accordance with principles for human experimentation as defined in the Declaration of Helsinki and were approved by the human investigational review board/ethics committee of each trial center, as required by International Council for Harmonisation of Technical Requirements for Pharmaceuticals for Human Use Guidelines for Good Clinical Practice.

Consent to participate Informed consent was obtained from each patient after each was informed of the potential risks and benefits, as well as the investigational nature of each trial.

Consent for publication The authors affirm that human research participants provided informed consent for publication of the study.

Open Access This article is licensed under a Creative Commons Attribution 4.0 International License, which permits use, sharing, adaptation, distribution and reproduction in any medium or format, as long as you give appropriate credit to the original author(s) and the source, provide a link to the Creative Commons licence, and indicate if changes were made. The images or other third party material in this article are included in the article's Creative Commons licence, unless indicated otherwise in a credit line to the material. If material is not included in the article's Creative Commons licence and your intended use is not permitted by statutory regulation or exceeds the permitted use, you will need to obtain permission directly from the copyright holder. To view a copy of this licence, visit http://creativecommons.org/licenses/by/4.0/.

\section{References}

1. von Pawel J, Schiller JH, Shepherd FA, Fields SZ, Kleisbauer JP, Chrysson NG, Stewart DJ, Clark PI, Palmer MC, Depierre A, Carmichael J, Krebs JB, Ross G, Lane SR, Gralla R (1999) Topotecan versus cyclophosphamide, doxorubicin, and vincristine for the treatment of recurrent small-cell lung cancer. J Clin Oncol 17(2):658-667. https://doi.org/10.1200/JCO.1999.17.2.658

2. von Pawel J, Gatzemeier U, Pujol JL, Moreau L, Bildat S, Ranson M, Richardson G, Steppert C, Riviere A, Camlett I, Lane S, Ross G (2001) Phase II comparator study of oral versus intravenous topotecan in patients with chemosensitive small-cell lung cancer. J Clin Oncol 19(6):1743-1749. https://doi.org/10.1200/JCO.2001. 19.6.1743

3. O'Brien ME, Ciuleanu TE, Tsekov H, Shparyk Y, Cucevia B, Juhasz G, Thatcher N, Ross GA, Dane GC, Crofts T (2006) Phase III trial comparing supportive care alone with supportive care with oral topotecan in patients with relapsed small-cell lung cancer. J Clin Oncol 24(34):5441-5447. https://doi.org/10.1200/JCO.2006. 06.5821

4. Eckardt JR, von Pawel J, Pujol JL, Papai Z, Quoix E, Ardizzoni A, Poulin R, Preston AJ, Dane G, Ross G (2007) Phase III study of oral compared with intravenous topotecan as second-line therapy in small-cell lung cancer. J Clin Oncol 25(15):2086-2092. https:// doi.org/10.1200/JCO.2006.08.3998 
5. von Pawel J, Jotte R, Spigel DR, O'Brien ME, Socinski MA, Mezger J, Steins M, Bosquee L, Bubis J, Nackaerts K, Trigo JM, Clingan P, Schutte W, Lorigan P, Reck M, Domine M, Shepherd FA, Li S, Renschler MF (2014) Randomized phase III trial of amrubicin versus topotecan as second-line treatment for patients with small-cell lung cancer. J Clin Oncol 32(35):4012-4019. https://doi.org/10.1200/JCO.2013.54.5392

6. Evans TL, Cho BC, Udud K, Fischer JR, Shepherd FA, Martinez P, Ramlau R, Syrigos KN, Shen L, Chadjaa M, Wolf M (2015) Cabazitaxel versus topotecan in patients with small-cell lung cancer with progressive disease during or after first-line platinumbased chemotherapy. J Thorac Oncol 10(8):1221-1228. https:// doi.org/10.1097/JTO.0000000000000588

7. Leal JF, Martinez-Diez M, Garcia-Hernandez V, Moneo V, Domingo A, Bueren-Calabuig JA, Negri A, Gago F, GuillenNavarro MJ, Aviles P, Cuevas C, Garcia-Fernandez LF, Galmarini CM (2010) PM01183, a new DNA minor groove covalent binder with potent in vitro and in vivo anti-tumour activity. Br J Pharmacol 161(5):1099-1110. https://doi.org/10.1111/j.1476-5381.2010. 00945.x

8. Santamaria Nunez G, Robles CM, Giraudon C, Martinez-Leal JF, Compe E, Coin F, Aviles P, Galmarini CM, Egly JM (2016) Lurbinectedin specifically triggers the degradation of phosphorylated RNA polymerase II and the formation of DNA breaks in cancer cells. Mol Cancer Ther 15(10):2399-2412. https://doi.org/ 10.1158/1535-7163.MCT-16-0172

9. Harlow M, Easton M, Guillén M PM01183 inactivates the EWS/ FLI1 transcription factor by redistributing the protein within the nucleus. 107th Annual Meeting of the American Association for Cancer Research; New Orleans, LA, USA; April 16-20, 2016 (abstr LB-177).

10. Belgiovine C, Bello E, Liguori M, Craparotta I, Mannarino L, Paracchini L, Beltrame L, Marchini S, Galmarini CM, Mantovani A, Frapolli R, Allavena P, D'Incalci M (2017) Lurbinectedin reduces tumour-associated macrophages and the inflammatory tumour microenvironment in preclinical models. Br J Cancer 117(5):628-638. https://doi.org/10.1038/bjc.2017.205

11. Singh S, Jaigirdar AA, Mulkey F, Cheng J, Hamed SS, Li Y, Liu J, Zhao H, Goheer A, Helms WS, Wang X, Agarwal R, Pragani R, Korsah K, Tang S, Leighton J, Rahman A, Beaver JA, Pazdur R, Theoret MR, Singh H (2020) FDA Approval Summary: Lurbinectedin for the treatment of metastatic small cell lung cancer. Clin Cancer Res. https://doi.org/10.1158/1078-0432.CCR-20-3901

12. Food and Drug Administration, CDER; Zepzelca ${ }^{\mathrm{TM}}$ Multi-disciplinary Review (2020). https://www.accessdata.fda.gov/drugs atfda_docs/nda/2020/213702Orig1s000MultidisciplineR.pdf.

13. Fernandez-Teruel C, Gonzalez I, Troconiz IF, Lubomirov R, Soto A, Fudio S (2018) Population-pharmacokinetic and covariate analysis of lurbinectedin (PM01183), a new RNA polymerase II inhibitor, in pooled phase I/II trials in patients with cancer. Clin Pharmacokinet 58(3):363-374. https://doi.org/10.1007/ s40262-018-0701-2

14. Elez ME, Tabernero J, Geary D, Macarulla T, Kang SP, Kahatt C, Pita AS, Teruel CF, Siguero M, Cullell-Young M, Szyldergemajn S, Ratain MJ (2014) First-in-human phase I study of Lurbinectedin (PM01183) in patients with advanced solid tumors. Clin Cancer Res 20(8):2205-2214. https://doi.org/10.1158/1078-0432. CCR-13-1880

15. Jimeno A, Sharma MR, Szyldergemajn S, Gore L, Geary D, Diamond JR, Fernandez Teruel C, Soto Matos-Pita A, Iglesias JL,
Cullell-Young M, Ratain MJ (2017) Phase I study of lurbinectedin, a synthetic tetrahydroisoquinoline that inhibits activated transcription, induces DNA single- and double-strand breaks, on a weekly x 2 every-3-week schedule. Invest New Drugs 35(4):471477. https://doi.org/10.1007/s10637-017-0427-2

16. Fernandez-Teruel C, Lubomirov R, Fudio S (2021) Population pharmacokinetic-pharmacodynamic modeling and covariate analyses of neutropenia and thrombocytopenia in patients with solid tumors treated with lurbinectedin. J Clin Pharmacol. https://doi. org/10.1002/jcph.1886

17. Trigo J, Subbiah V, Besse B, Moreno V, Lopez R, Sala MA, Peters S, Ponce S, Fernandez C, Alfaro V, Gomez J, Kahatt C, Zeaiter A, Zaman K, Boni V, Arrondeau J, Martinez M, Delord JP, Awada A, Kristeleit R, Olmedo ME, Wannesson L, Valdivia J, Rubio MJ, Anton A, Sarantopoulos J, Chawla SP, Mosquera-Martinez J, D'Arcangelo M, Santoro A, Villalobos VM, Sands J, Paz-Ares L (2020) Lurbinectedin as second-line treatment for patients with small-cell lung cancer: a single-arm, open-label, phase 2 basket trial. Lancet Oncol 21(5):645-654. https://doi.org/10.1016/S14702045(20)30068-1

18. Eisenhauer EA, Therasse P, Bogaerts J, Schwartz LH, Sargent D, Ford R, Dancey J, Arbuck S, Gwyther S, Mooney M, Rubinstein L, Shankar L, Dodd L, Kaplan R, Lacombe D, Verweij J (2009) New response evaluation criteria in solid tumours: revised RECIST guideline (version 1.1). European journal of cancer (Oxford, England : 1990) 45 (2):228-247. doi:http://doi. org/https://doi.org/10.1016/j.ejca.2008.10.026

19. Lindbom L, Pihlgren P, Jonsson EN (2005) PsN-Toolkit-a collection of computer intensive statistical methods for non-linear mixed effect modeling using NONMEM. Comput Methods Programs Biomed 79(3):241-257. https://doi.org/10.1016/j.cmpb.2005.04. 005

20. Jonsson EN, Karlsson MO (1998) Xpose-an S-PLUS based population pharmacokinetic/pharmacodynamic model building aid for NONMEM. J Biomechanics 58(1):51-64. https://doi.org/ 10.1016/s0169-2607(98)00067-4

21. Wickham H (2009) ggplot2. Elegant graphics for data analysis New York: Springer-Verlag. https://doi.org/10.1007/ 978-0-387-98141-3

22. Haouala A, Widmer N, Guidi M, Montemurro M, Leyvraz S, Buclin T, Eap CB, Decosterd LA, Csajka C (2013) Prediction of free imatinib concentrations based on total plasma concentrations in patients with gastrointestinal stromal tumours. Br J Clin Pharmacol 75(4):1007-1018. https://doi.org/10.1111/j.1365-2125.2012. 04422.x

23. Ouellet D (2010) Benefit-risk assessment: the use of clinical utility index. Expert Opin Drug Saf 9(2):289-300. https://doi.org/10. 1517/14740330903499265

24. Benet LZ, Hoener BA (2002) Changes in plasma protein binding have little clinical relevance. Clin Pharmacol Ther 71(3):115-121. https://doi.org/10.1067/mcp.2002.121829

Publisher's Note Springer Nature remains neutral with regard to jurisdictional claims in published maps and institutional affiliations. 